\title{
What built environmental factors mitigate decline in older adults' step count? Three-year longitudinal study with a large sample in Yokohama, Japan
}

Kimihiro Hino ( $\boldsymbol{D}$ hino@ua.t.u-tokyo.ac.jp )

The University of Tokyo https://orcid.org/0000-0003-1243-1329

Hiroyuki Usui

The University of Tokyo

Masamichi Hanazato

Chiba University

\section{Research}

Keywords: Physical activity, Neighborhood, Multilevel analysis, Walkability, Compact city

Posted Date: April 9th, 2020

DOI: https://doi.org/10.21203/rs.3.rs-21527/v1

License: (c) (i) This work is licensed under a Creative Commons Attribution 4.0 International License.

Read Full License 


\section{Abstract}

Background: Neighborhood walkability achieved through land-use and transport planning is an important determinant of physical activity, especially for older adults who spend more time in their neighborhoods than do other ages. This three-year study aimed to examine the longitudinal association between the change in the step count of older adults and the built environment (BE) around their homes in Yokohama, Japan.

Methods: We analyzed pedometer data in March 2016 and March 2019 that was acquired from 21557 older adults aged 65-79 years at baseline, who lived in 758 neighborhoods in Yokohama city who participated in the Yokohama Walking Point Program (YWPP). Neighborhoods were classified into quartiles for each of the six built environmental variables (population density, intersection density, the proportion of commercial land use, normalized difference vegetation index (NDVI), the average distance to the nearest railway station, and average distance to the nearest bus stop), which were selected based on previous studies. Using multilevel regression analysis, we examined the connection between the BE variables, baseline step count, and the change in step count during the three years.

Results: Higher population density, lower intersection density, and the second shortest quartile of the average distance to the nearest railway station were associated with a higher baseline step count. A lower intersection density and shorter average distance to the nearest railway station were associated with a smaller decline. The lowest quartile of population density was reversely associated. Additionally, female and older groups recorded a lower baseline step count and a larger decline. A higher baseline step count was associated with a larger decline, as well.

Conclusions: The neighborhood BEs (i.e., population density, intersection density, and average distance to the nearest railway station) of older adults were not only associated with their step count at a certain time point, but also widened the disparity of the step count over the three years. Urban planners and designers should place emphasis on interdisciplinary collaboration with health promotion professionals in order to create compact cities centered around railway stations that are protected from traffic, so older adults feel safe.

\section{Background}

The promotion of regular physical activity (PA) decreases the risk of non-communicable diseases and increases life expectancy [1]. Older adults, in particular, can benefit from regular PA to maintain their physical, social, and mental health, as well as decrease the risk of dementia. [2, 3].

To promote PA for a population, a walkable built environment (BE) achieved through land-use and transport planning is essential $[4,5]$. The attributes of a walkable BE, known as the "5Ds" (i.e., Density, Diversity, Design, Destination accessibility, and Distance to transit), are well known. [6, 7]. Such attributes would be more influential for older adults whose geographic reach of activity space is smaller and who spend more time in their neighborhoods than other ages $[8,9]$. 
Previous studies have examined associations between older adults' walking and/or PA and the 5D attributes: density (e.g., population density and household density) [10, 11], diversity (e.g., land use mix and green land use) [10,12-14], design (e.g., intersection density and street connectivity) $[6,10,11,13$, 14], destination accessibility (e.g., accessibility to amenities, commercial facilities, and services) [10,1316], and distance to transit [17]. However, these were cross-sectional studies, while longitudinal studies are needed to avoid the self-selection bias and establish causal relationships between the BE and PA [18, 19]. In other words, the accumulation of longitudinal studies is required to confirm the observed associations between the BE and PA found in cross-sectional studies [13].

A few studies examined the relationship between the longitudinal change of walking and/or PA of older adults and the BE factors, i.e., access to PA facilities [20], proximity to parks and trails [21], closeness to functional spaces (e.g., supermarkets and PA facilities) [22], proximity to services and amenities [23], living in greener neighborhoods [24], and combined walkability score [25]. However, these studies considered only some of the 5D attributes and used self-reported data of PA.

Thus, this study aims to examine the association between the change in the step count of older adults over three years and the BE around their homes in Yokohama, Japan. For comparison, the association between their baseline step counts and their BE is examined, as well. The uniqueness of this study lies in that the step count from a large sample, and the BE variables based on all of the 5Ds were objectively measured and analyzed longitudinally.

\section{Methods}

\section{Target Area}

The target area of this study was the 758 neighborhoods (postal code area) that constitute Yokohama city, the second most populous city in Japan with a population of approximately 3.75 million people, of which $27.1 \%$ are 65 years or older as of January 2020. Located $30-40 \mathrm{~km}$ from Tokyo, the city's railway network has been developed with many lines running toward central Tokyo and has 157 railway stations (Fig. 1). Like other big cities in Japan, railway stations in Yokohama host a comprehensive set of services and products [26], serving as a destination for residents. The local bus network has been expanded around the railway stations, enabling approximately $90 \%$ of the citizens access to the railway stations within 15 minutes.

\section{Measurements}

\section{Step count data}

Step count data was obtained from older participants (aged 65-79 years) of the Yokohama Walking Point Program (YWPP), which the city launched in November 2014 to encourage citizens to improve their health and healthy life expectancy. It provided free pedometers (Omron HJ-326F, Japan) for volunteers 
aged 18 years and above who live and/or work in Yokohama. Participants were awarded points based on their step count by scanning their pedometers via special readers installed at approximately 1000 stores and other facilities in the city. The accumulation of a certain number of points made participants eligible to win prizes. The scanned data were sent to a data server through the Internet, allowing participants to monitor their step count and rank among all the participants using a computer or smartphone [27].

We used the data from March 2016 (baseline) and March 2019 (endline). The climate in Yokohama in March is mild. The average minimum and maximum temperatures on March 2016 were $7.0^{\circ} \mathrm{C}$ and $14.5^{\circ} \mathrm{C}$, respectively, while those on March 2019 were $7.3^{\circ} \mathrm{C}$ and $15.1^{\circ} \mathrm{C}$, respectively [28]. The average step count of participants aged 65 or older in March 2016 was the seventh highest of the preceding 12 months, starting in April 2015 [29].

The sample of this study was selected from 303629 YWPP participants (as of the end of March 2019). We excluded participants aged less than 65 or more than 79 (60.0\%), and participants whose record for participation in March 2016 or March 2019 was less than 16 days ( $74.8 \%$ and $75.0 \%$, respectively). We further excluded participants whose addresses were outside of Yokohama city (4.2\%), decreasing the number of participants to 22357 . Finally, 101 participants whose postal codes had changed during the three-year period, and 699 participants whose step count in March 2016 and/or March 2019 was in either the upper or lower $1 \%$ of the remaining participants were excluded as outliers. A resulting total of 21557 participants was selected as the sample of this study (Fig. 2).

\section{Built environment variables and control variables}

Six BE variables selected based on the 5Ds were computed using ArcMap 10.6 (Esri, Redlands, CA) and used in the following analyses. Neighborhoods were classified into quartiles for each BE variable.

First, population density (per ha) was used as an index of density (Fig. 1), calculated based on the population census conducted in 2015. Second, intersection density (per ha) was used as an index of design following previous studies $[6,10,11]$. The source of information was the Advanced Digital Road Map Database 2013 (Sumitomo Electric Industries, Ltd., Osaka, Japan). Third, the proportion of commercial land use (\%) was used as an index of diversity and destination, calculated based on the result of the Basic Surveys Concerning City Planning in 2013 provided by Yokohama city. Fourth, the normalized difference vegetation index (NDVI), as of 2016, was used as an index of diversity and destination, as well. The NDVI quantifies vegetation by measuring the difference between near-infrared light (which vegetation strongly reflects) and red light (which vegetation absorbs). It ranges from -1 to + 1. When it is positive, the land cover is likely to be green vegetation, including parks and promenades, which can be destinations for residents. On the other hand, when negative, the land cover is likely to be street surfaces and buildings. The NDVI was selected as a BE variable because green land use was associated with older adults' PA in both cross-sectional [30] and longitudinal studies [24]. Fifth, the average distance to the nearest railway station $(\mathrm{km})$ was used as an index of distance to transit and destination. It was calculated using data from the National Land Numerical Information download 
service [31], as of 2018. Lastly, the average distance to the nearest bus stop $(\mathrm{km})$ was used as an index of distance to transit, which was calculated using data from the same service, as of 2010. Considering the shared role between railways and buses in Yokohama, as mentioned above, the average distance to the nearest railway station and bus stop should be separate variables, although most previous studies did not separate the two $[14,32]$. As the precise address of each participant was unknown, the distance to the nearest railway station and bus stop from each participant's address was computed by measuring the distance from the 50-meter grid points within each neighborhood, calculating the average for each neighborhood.

Although many studies used a composite measure of walkability $[17,25,33-36]$, this study uses BE variables without compounding them because composite measures are less useful for urban planners and designers as they cannot know the effect of each BE variable. The control variables in both analyses were participants' sex, age group (65-69, 70-74, and 75-79 years old; as of March 2016).

\section{Statistical analysis}

As our data had a multilevel structure with individuals at level one nested within 758 neighborhoods, at level two, we performed multilevel regression analyses with random intercepts. The outcome variables were step count at the baseline in the first analysis, and the change in step count during the three-year period for the second analysis. The explanatory variables were the six BE variables and control variables of sex and age group in the first analysis, and baseline step count was added in the second analysis. The significance level was set at $p<0.05$. All statistical analyses were conducted using IBM SPSS Statistics 26 (IBM Corp., Armonk, NY, USA).

\section{Results}

\section{Descriptive statistic}

The descriptive statistics of the sample are presented in Table 1. Males constituted $48 \%$ of the sample. The age groups $65-69$ years, $70-74$ years, and $75-79$ years constituted $43 \%, 35 \%$, and $22 \%$ of the sample, respectively. The average step count at the baseline was $7699.0 \pm 3252.1$, and the endline was $6845.3 \pm 3252.1$, representing that the step count of the sample decreased by an average of 850 steps during the three-year trial. 
Table 1

Descriptive statistics of the sample $(N=$

\begin{tabular}{|llll|}
\hline \multicolumn{4}{|c}{ 21557) } \\
\hline & & $\mathbf{n}$ & $\%$ \\
\hline Sex & Male & 10303 & $48 \%$ \\
\hline & Female & 11254 & $52 \%$ \\
\hline Age (in years) & $65-69$ & 9359 & $43 \%$ \\
\hline & $70-74$ & 7507 & $35 \%$ \\
\hline $79-79$ & 4691 & $22 \%$ \\
\hline
\end{tabular}

Descriptive statistics of the BE variables of 758 neighborhoods are presented in Table 2. The median of population density and intersection density per ha were 115.60 and 2.03 , respectively. The proportion of commercial land use was generally low, and the median was 3.3\%. The NDVI was positive in all neighborhoods. The median of the average distance to the nearest railway station and the nearest bus stop was $647 \mathrm{~m}$ and $175 \mathrm{~m}$, respectively, representing the convenience of public transportation in Yokohama.

Table 2

Descriptive statistics of BE variables of 758 neighborhoods

\begin{tabular}{|c|c|c|c|c|c|c|c|}
\hline & Min & Max & Mean & SD & $\begin{array}{l}\text { 1st } \\
\text { quartile }\end{array}$ & Median & $\begin{array}{l}\text { 3rd } \\
\text { quartile }\end{array}$ \\
\hline Population density (per ha) & 0 & 723.30 & 116.66 & 79.11 & 68.28 & 115.60 & 148.38 \\
\hline Intersection density (per ha) & 0 & 7.72 & 2.09 & 1.18 & 1.33 & 2.03 & 2.76 \\
\hline $\begin{array}{l}\text { Proportion of commercial land } \\
\text { use }(\%)\end{array}$ & 0.0 & 51.2 & 6.0 & 7.6 & 1.5 & 3.3 & 6.8 \\
\hline NDVI & 0.01 & 0.34 & 0.08 & 0.05 & 0.05 & 0.08 & 0.10 \\
\hline $\begin{array}{l}\text { Average distance to the } \\
\text { nearest } \\
\text { railway station }(\mathrm{km})\end{array}$ & 0.07 & 3.99 & 0.817 & 0.618 & 0.362 & 0.647 & 1.056 \\
\hline bus stop (km) & 0.06 & 1.72 & 0.197 & 0.103 & 0.141 & 0.175 & 0.225 \\
\hline
\end{tabular}

\section{Multilevel regression analyses}

The results of the multilevel regression analyses are presented in Table 3. 
Table 3

Associations between BE variables and step count (baseline and change) using multilevel regression $(N=21,557)$

\begin{tabular}{|c|c|c|c|c|c|c|}
\hline & \multicolumn{3}{|c|}{ Baseline step counts } & \multicolumn{3}{|c|}{ Change in step counts } \\
\hline & B & $95 \% \mathrm{Cl}$ & $\mathrm{P}$ & B & $95 \% \mathrm{Cl}$ & $\mathrm{P}$ \\
\hline \multicolumn{7}{|l|}{ BE variables } \\
\hline \multicolumn{7}{|c|}{ Population density (ref: Q4) } \\
\hline Q1 (Lowest) & -213.7 & $(-396,-31.3)$ & 0.022 & -115.9 & $(-225.9,-5.9)$ & 0.039 \\
\hline Q2 & -118.9 & $(-262.1,24.4)$ & 0.104 & -10.8 & $(-97.6,76)$ & 0.807 \\
\hline Q3 & -113.3 & $(-250.4,23.7)$ & 0.105 & -4.3 & $(-87.4,78.8)$ & 0.919 \\
\hline \multicolumn{7}{|c|}{ Intersection density (ref: Q4) } \\
\hline Q1 (Lowest) & 208.0 & $(52.5,363.4)$ & 0.009 & 87.9 & $(-5.4,181.3)$ & 0.065 \\
\hline Q2 & 50.7 & $(-75.6,177)$ & 0.430 & 129.7 & $(53.3,206.2)$ & 0.001 \\
\hline Q3 & -37.0 & $(-157.4,83.4)$ & 0.545 & 31.9 & $(-41,104.8)$ & 0.391 \\
\hline \multicolumn{7}{|c|}{ Average distance to the nearest railway station (ref: Q4) } \\
\hline Q1 (Shortest) & 120.5 & $(-49.2,290.2)$ & 0.163 & 130.7 & $(27.9,233.5)$ & 0.013 \\
\hline Q2 & 200.0 & $(73.1,326.9)$ & 0.002 & 117.5 & $(40.7,194.3)$ & 0.003 \\
\hline Q3 & 110.0 & $(-3.8,223.8)$ & 0.058 & 117.1 & $(48.6,185.6)$ & 0.001 \\
\hline \multicolumn{7}{|l|}{ Control variables } \\
\hline \multicolumn{7}{|l|}{ Sex (ref: Female) } \\
\hline Male & 1821.7 & $(1738.4,1905)$ & 0.000 & 358.6 & $(304.3,412.8)$ & 0.000 \\
\hline \multicolumn{7}{|l|}{ Age (ref: 75-79) } \\
\hline $65-69$ & 815.4 & $(705.8,925)$ & 0.000 & 314.9 & $(246.1,383.8)$ & 0.000 \\
\hline $70-74$ & 460.7 & $(347,574.4)$ & 0.000 & 154.0 & $(82.7,225.2)$ & 0.000 \\
\hline Baseline step counts & - & - & - & -0.3 & $(-0.3,-0.3)$ & 0.000 \\
\hline
\end{tabular}

In the first analysis with the outcome variable of step count at the baseline, a higher population density and lower intersection density were associated with a higher baseline step count. The association between the average distance to the nearest railway station and baseline step count was nonlinear; however, the second shortest quartile (Q2) was associated with a significantly higher baseline step count. Other BE variables: the proportion of commercial land use, the NDVI, and the average distance to the nearest bus stop, were not significant. 
In the second analysis with the outcome variable of change in step count during the three years, the lowest quartile (Q1) of population density was associated with a larger decline. In addition, lower intersection density and shorter average distance to the nearest railway station were associated with a smaller decline in step count. The other three BE variables were not significant.

Regarding control variables over the course of the study, being female was associated with a lower baseline step count and larger decline, as was being in the older age group. Additionally, a higher baseline step count was associated with a larger decline.

[Table 3 should appear here]

\section{Discussion}

This study examined the association between the change in step count of older adults and the BE around their homes in Yokohama, Japan, over a three-year period. The main finding was that of the 5Ds, four of the Ds (Density, Diversity, Destination accessibility, and Distance to transit) mitigated the decline in older adults' step count corresponding with previous cross-sectional studies relating to walking and/or the PA of older adults. In addition, the association of the BE with baseline step count was examined.

Comparisons of the results of the two models showed that the significant variables selected were mostly the same, and the direction of the coefficients was consistent in both models. In other words, the BEs of older adults were not only associated with their step count at a certain time point but also widened the disparity of their step count over the three years.

Regarding each variable, a lower population density was associated with a lower baseline step count, and older adults living in the lowest quartile neighborhoods of population density had significantly decreased step count during the three years. This result is consistent with a previous study that found higher baseline levels of population density were associated with greater increases in walking for transportation, although the sample was not limited to older adults [37]. Population density ensures public transport and local shops and services are more viable [38] and serves as a proxy variable showing the convenience of walking for local residents. Older adults in sparsely-populated and inconvenient areas might decrease their trip frequency or change their transportation mode from walking. It was estimated that the population of Yokohama reached its peak in 2019 and would begin declining as cities in Japan [39]. On a micro-scale level, areas that are inconvenient to reach in the city would experience a greater decrease in population, resulting in the withdrawal of facilities and even greater inconvenience to residents. Considering low residential mobility in Japan, especially that of older adults [40], health promotion interventions for PA would be necessary for such areas.

Inversely, lower intersection density was associated with higher baseline step count and a smaller decline in step count over the course of the study. High intersection density indicates there are many route opportunities for traversing a road network and is thought to promote walking [6], as previous crosssectional studies have shown, there is a positive association between older adults' self-reported walking and intersection density $[10,11]$. In previous longitudinal studies, not limited to older adults, higher street 
connectivity proved to be associated with a greater increase in walking for transportation [37, 41]. Although our results contradicted these studies, another study conducted in Japan also stated that the number of intersections was negatively associated with walking time [42]. It may be that intersection density cannot be an index of walkability in a city with high intersection density like Yokohama. The intersection density in Yokohama is approximately twice the figure compared to 100 cities all over the world, excluding Japanese cities, and as high as the highest city (Lisbon, Portugal) in developed countries [43]. Considering a previous study that showed that the number of street intersections contributed to walking activity only when residents perceived that the traffic conditions were safe [11]; the older adults in neighborhoods with a high intersection density in this study might feel unsafe as intersection density acted as an index of traffic accident risk.

Regarding the average distance to the nearest railway station, older adults living in the second closest quartile neighborhood recorded a significantly higher baseline step count, which suggests that they could not walk much when living too close to stations. A walkable design where older adults feel safe and are more willing to walk around is desirable around railway stations. More importantly, it was found that older adults living closer to railway stations experienced a smaller decline in step count. Taking this into consideration with a previous study of older Japanese showing a lower risk of functional limitations among those using public transport after driving cessation [44], closeness to railway stations would enable older adults to maintain their active living, their step count, and their health even after they give up driving. Yokohama city aims to accumulate residential functions around railway stations, even in suburban areas, as well as commercial and business functions [45]. Such a compact city policy, which is thought to positively influence the overall health of city populations [46], would be more beneficial in an aging society like Yokohama city provided that consideration is given to outskirt areas, as noted above.

The other BE variables, the proportion of commercial land use, the NDVI, and the average distance to the nearest bus stop, were not significantly associated with step counts in either regression analyses. It might be because of their strong correlation with the other BE variables. Regarding personal attributes, females and the older group recorded a lower baseline step count and a larger decline over the course of the study. Additionally, a higher baseline step count was associated with a larger decline, which was consistent with a previous study [20].

While making an important contribution to existing research on $\mathrm{BE}$ factors that mitigate the decline in the step count of older adults, this study has limitations. For instance, previous studies showed social environmental factors, such as neighborhood cohesion [47], income deprivation [48], participation with friends [49], social support [34], and neighbor relationships [50], were associated with walking and/or PA. Unfortunately, this study was not able to assess the impact of social environments of older adults as it is difficult to collect data on social environmental factors from a large sample. Therefore, future studies should consider them when examining the longitudinal association between changes in older adults' PA. In addition, study participants may not be representative of the general population of Yokohama city in that they were motivated to have pedometers, suggesting a greater intention to walk than others. We 
thought that study participants would be less affected by the BE because of their higher motivation and that the effect of the BE would be underestimated in this study.

\section{Conclusion}

The importance of this study lies in the large sample size for which step count was measured longitudinally. The neighborhood BEs of older adults were not only associated with their step count during a certain time period, but also widened the disparity of the step count during the three-year study. It is essential that urban planners and designers place emphasis on interdisciplinary collaboration with health professionals to create compact cities centered around railway stations that are protected from traffic to ensure the safety of older adults.

\section{Abbreviations}

PA: Physical Activity; BE: Built Environment; Cl: Confidence intervals; YWPP: Yokohama Walking Point Program; NDVI: Normalized Difference Vegetation Index

\section{Declarations}

\section{Ethics approval and consent to participate}

The study protocol was approved by the Ethical Committee of School of Engineering, the University of Tokyo (approved July 2015). All participants provided written informed consent.

\section{Consent for publication}

Not applicable.

\section{Availability of data and materials}

The data that support the findings of this study are able to be obtained from Yokohama city, but restrictions apply to the availability of these data. They were used under an agreement for the current study, and so are not publicly available.

\section{Competing interests}

The authors declare that they have no competing interests.

\section{Funding}

This research was supported by JSPS KAKENHI, grant number $18 \mathrm{H} 01602$.

\section{Author Contributions}


KH designed this study, acquired and analyzed data, and drafted the manuscript. $\mathrm{MH}$ and $\mathrm{HU}$ assisted with acquisition and interpretation of data, and critically reviewed the manuscript. All authors approved the final version of the manuscript.

\section{Acknowledgments}

The authors thank the staff of Yokohama city for their generous support of this research and T. Miyagawa for helping us collect the data.

\section{References}

1. Lee I-M, Shiroma EJ, Lobelo F, Puska P, Blair SN, Katzmarzyk PT. Effect of physical inactivity on major non-communicable diseases worldwide: an analysis of burden of disease and life expectancy. Lancet. 2012;380:219-29.

2. World Health Organization. Global action plan on physical activity 2018-2030: more active people for a healthier world. World Heal. Organ. Geneva; 2018.

3. Sallis JF, Bull F, Guthold R, Heath GW, Inoue S, Kelly P, et al. Progress in physical activity over the Olympic quadrennium. Lancet Elsevier Ltd. 2016;388:1325-36.

4. Sallis JF, Bull F, Burdett R, Frank LD, Griffiths P, Giles-Corti B, et al. Use of science to guide city planning policy and practice: how to achieve healthy and sustainable future cities. Lancet Elsevier Ltd. 2016;388:2936-47.

5. Giles-Corti B, Vernez-Moudon A, Reis R, Turrell G, Dannenberg AL, Badland H, et al. City planning and population health: a global challenge. Lancet Elsevier Ltd. 2016;388:2912-24.

6. Cervero R, Sarmiento OL, Jacoby E, Gomez LF, Neiman A. Influences of built environments on walking and cycling: Lessons from Bogotá. Int J Sustain Transp. 2009;3:203-26.

7. City of New York. Active Design Guidelines: Promoting Physical Activity and Health in Design. 2010.

8. Kim S, Ulfarsson GF. Activity Space of Older and Working-Age Adults in the Puget Sound Region, Washington. Transp Res Rec J Transp Res Board. 2015;2494:37-44.

9. Kerr J, Rosenberg D, Frank L. The Role of the Built Environment in Healthy Aging: Community Design, Physical Activity, and Health among Older Adults. J Plan Lit. 2012;27:43-60.

10. Troped PJ, Tamura K, McDonough MH, Starnes HA, James P, Ben-Joseph E, et al. Direct and Indirect Associations Between the Built Environment and Leisure and Utilitarian Walking in Older Women. Ann Behav Med Annals of Behavioral Medicine. 2017;51:282-91.

11. Li F, Fisher KJ, Brownson RC, Bosworth M. Multilevel modelling of built environment characteristics related to neighbourhood walking activity in older adults. J Epidemiol Community Health. 2005;59:558-64.

12. Kolbe-Alexander TL, Pacheco K, Tomaz SA, Karpul D, Lambert EV. The relationship between the built environment and habitual levels of physical activity in South African older adults: A pilot study Health behavior, health promotion and society. BMC Public Health. 2015;15:1-9. 
13. Holle V, Van, Van Cauwenberg J, Gheysen F, Van Dyck D, Deforche B, Van De Weghe N, et al. The association between Belgian older adults' physical functioning and physical activity: What is the moderating role of the physical environment? PLoS One. 2016;11:1-17.

14. Nyunt MSZ, Shuvo FK, Eng JY, Yap KB, Scherer S, Hee LM, et al. Objective and subjective measures of neighborhood environment (NE): Relationships with transportation physical activity among older persons. Int J Behav Nutr Phys Act International Journal of Behavioral Nutrition Physical Activity. 2015;12:1-10.

15. King WC, Brach JS, Belle S, Killingsworth R, Fenton M, Kriska AM. The relationship between convenience of destinations and walking levels in older women. Am J Heal Promot. 2003;18:74-82.

16. Etman A, Kamphuis CBM, Prins RG, Burdorf A, Pierik FH, van Lenthe FJ. Characteristics of residential areas and transportational walking among frail and non-frail Dutch elderly: Does the size of the area matter? Int J Health Geogr. 2014;13:1-7.

17. Clarke P, Gallagher NA. Optimizing mobility in later life: The role of the urban built environment for older adults aging in place. J Urban Heal. 2013;90:997-1009.

18. Cerin E, Nathan A, van Cauwenberg J, Barnett DW, Barnett A. The neighbourhood physical environment and active travel in older adults: A systematic review and meta-analysis. Int J Behav Nutr Phys Act International Journal of Behavioral Nutrition Physical Activity. 2017;14:1-23.

19. Barnett DW, Barnett A, Nathan A, Van Cauwenberg J, Cerin E. Built environmental correlates of older adults' total physical activity and walking: A systematic review and meta-analysis. Int J Behav Nutr Phys Act International Journal of Behavioral Nutrition Physical Activity. 2017;14:1-24.

20. Li F, Fisher KJ, Brownson RC. A multilevel analysis of change in neighborhood walking activity in older adults. J Aging Phys Act. 2005;13:145-59.

21. Michael YL, Perdue LA, Orwoll ES, Stefanick ML, Marshall LM. Physical activity resources and changes in walking in a cohort of older men. Am J Public Health. 2010;100:654-60.

22. Zhou P, Grady SC, Chen G. How the built environment affects change in older people's physical activity: A mixed- methods approach using longitudinal health survey data in urban China. Soc Sci Med. Elsevier Ltd; 2017;192:74-84.

23. Gauvin L, Richard L, Kestens Y, Shatenstein B, Daniel M, Moore SD, et al. Living in a well-serviced urban area is associated with maintenance of frequent walking among seniors in the VoisiNuAge study. Journals Gerontol - Ser B Psychol Sci Soc Sci. 2012;67 B:76-88.

24. Dalton AM, Wareham N, Griffin S, Jones AP. Neighbourhood greenspace is associated with a slower decline in physical activity in older adults: A prospective cohort study. SSM - Popul Heal. 2016;2:683-91.

25. Kikuchi H, Nakaya T, Hanibuchi T, Fukushima N, Amagasa S, Oka K, et al. Objectively measured neighborhood walkability and change in physical activity in older Japanese adults: A five-year cohort study. Int J Environ Res Public Health. 2018;15:1814.

26. Zacharias J, Zhang T, Nakajima N. Tokyo Station City: The railway station as urban place. Urban Des Int. $2011 ; 16: 242-51$. 
27. Hino K, Taniguchi A, Hanazato M, Takagi D. Modal shift from cars and promotion of walking by providing pedometers in Yokohama city, Japan. Int J Environ Res Public Health. 2019;16.

28. Japan Meteorological Agency. Meteorological data search service. 2020. . Accessed 8 Mar 2020.

29. Hino K, Lee JS, Asami Y. Associations between seasonal meteorological conditions and the daily step count of adults in Yokohama, Japan: Results of year-round pedometer measurements in a large population. Prev Med Reports. 2017;8:15-7.

30. Gong Y, Gallacher J, Palmer S, Fone D. Neighbourhood green space, physical function and participation in physical activities among elderly men: The Caerphilly Prospective study. Int J Behav Nutr Phys Act. 2014;11:1-11.

31. Ministry of Land Infrastructure Transport and Tourism. National Land Numerical Information download service. 2020. . Accessed 16 Mar 2020.

32. Todd M, Adams MA, Kurka J, Conway TL, Cain KL, Buman MP, et al. GIS-measured walkability, transit, and recreation environments in relation to older Adults' physical activity: A latent profile analysis. Prev Med (Baltim). 2016;93:57-63.

33. Gao J, Fu H, Li J, Jia Y. Association between social and built environments and leisure-time physical activity among Chinese older adults - a multilevel analysis. BMC Public Health BMC Public Health. 2015;15:1317.

34. Carlson JA, Sallis JF, Conway TL, Saelens BE, Frank LD, Kerr J, et al. Interactions between psychosocial and built environment factors in explaining older adults' physical activity. Prev Med (Baltim). Elsevier Inc.; 2012;54:68-73.

35. Chudyk AM, McKay HA, Winters M, Sims-Gould J, Ashe MC. Neighborhood walkability, physical activity, and walking for transportation: A cross-sectional study of older adults living on low income. BMC Geriatr BMC Geriatrics. 2017;17:1-14.

36. Hanibuchi T, Nakaya T, Yonejima M, Honjo K. Perceived and objective measures of neighborhood walkability and physical activity among adults in Japan: A multilevel analysis of a nationally representative sample. Int J Environ Res Public Health. 2015;12:13350-64.

37. Hirsch JA, Moore KA, Clarke PJ, Rodriguez DA, Evenson KR, Brines SJ, et al. Changes in the built environment and changes in the amount of walking over time: Longitudinal results from the MultiEthnic study of Atherosclerosis. Am J Epidemiol. 2014;180:799-809.

38. Udell T, Daley M, Johnson B, Tolley DR. Does Density Matter? The role of density in creating walkable neighbourhoods. Natl. Hear. Found. Aust. 2014.

39. Yokohama city. Population estimation in Yokohama. 2019. . Accessed 22 Mar 2020.

40. Chiuri MC, Jappelli T. Do the elderly reduce housing equity? An international comparison. J Popul Econ. 2010;23:643-63.

41. Knuiman MW, Divitini ML, Foster SA, Christian HE, Giles-Corti B, Bull FC, et al. A Longitudinal Analysis of the Influence of the Neighborhood Built Environment on Walking for Transportation: The RESIDE Study. Am J Epidemiol. 2014;180:453-61. 
42. Hanibuchi T, Kawachi I, Nakaya T, Hirai H, Kondo K. Neighborhood built environment and physical activity of Japanese older adults: Results from the Aichi Gerontological Evaluation Study (AGES). BMC Public Health. 2011;11.

43. Rashid M. The Geometry of Urban Layouts. Cham: Springer International Publishing; 2017.

44. Hirai H, Ichikawa M, Kondo N, Kondo K. The Risk of Functional Limitations After Driving Cessation Among Older Japanese Adults: The JAGES Cohort Study. J Epidemiol. 2019; JE20180260.

45. Yokohama city. Yokohama City Transportation Plan. Yokohama, Kanagawa, Japan; 2018.

46. Stevenson M, Thompson J, de Sá TH, Ewing R, Mohan D, McClure R, et al. Land use, transport, and population health: estimating the health benefits of compact cities. Lancet. 2016;388:2925-35.

47. Li Y, Kao D, Dinh TQ. Correlates of neighborhood environment with walking among older Asian Americans. J Aging Health. 2015;27:17-34.

48. Hawkesworth S, Silverwood RJ, Armstrong B, Pliakas T, Nanchalal K, Jefferis BJ, et al. Investigating associations between the built environment and physical activity among older people in 20 UK towns. J Epidemiol Community Health. 2018;72:121-31.

49. Chaudhury H, Campo M, Michael Y, Mahmood A. Neighbourhood environment and physical activity in older adults. Soc Sci Med Elsevier Ltd. 2016;149:104-13.

50. Seino S, Kitamura A, Nishi M, Tomine Y, Tanaka I, Taniguchi Y, et al. Individual- and community-level neighbor relationships and physical activity among older Japanese adults living in a metropolitan area: A cross-sectional multilevel analysis. Int J Behav Nutr Phys Act International Journal of Behavioral Nutrition Physical Activity. 2018;15:1-11.

\section{Figures}




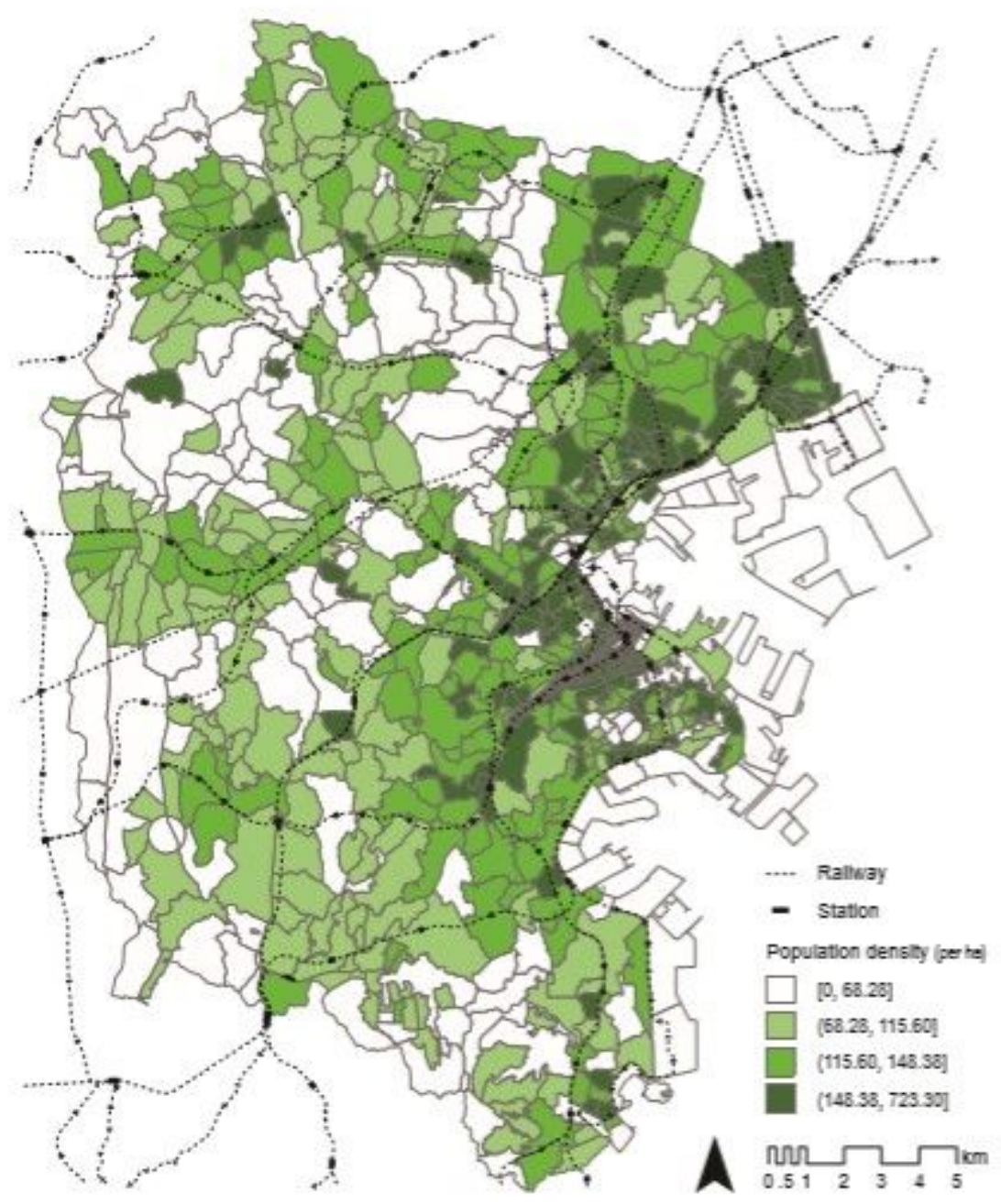

Figure 1

Target area (Yokohama city) 


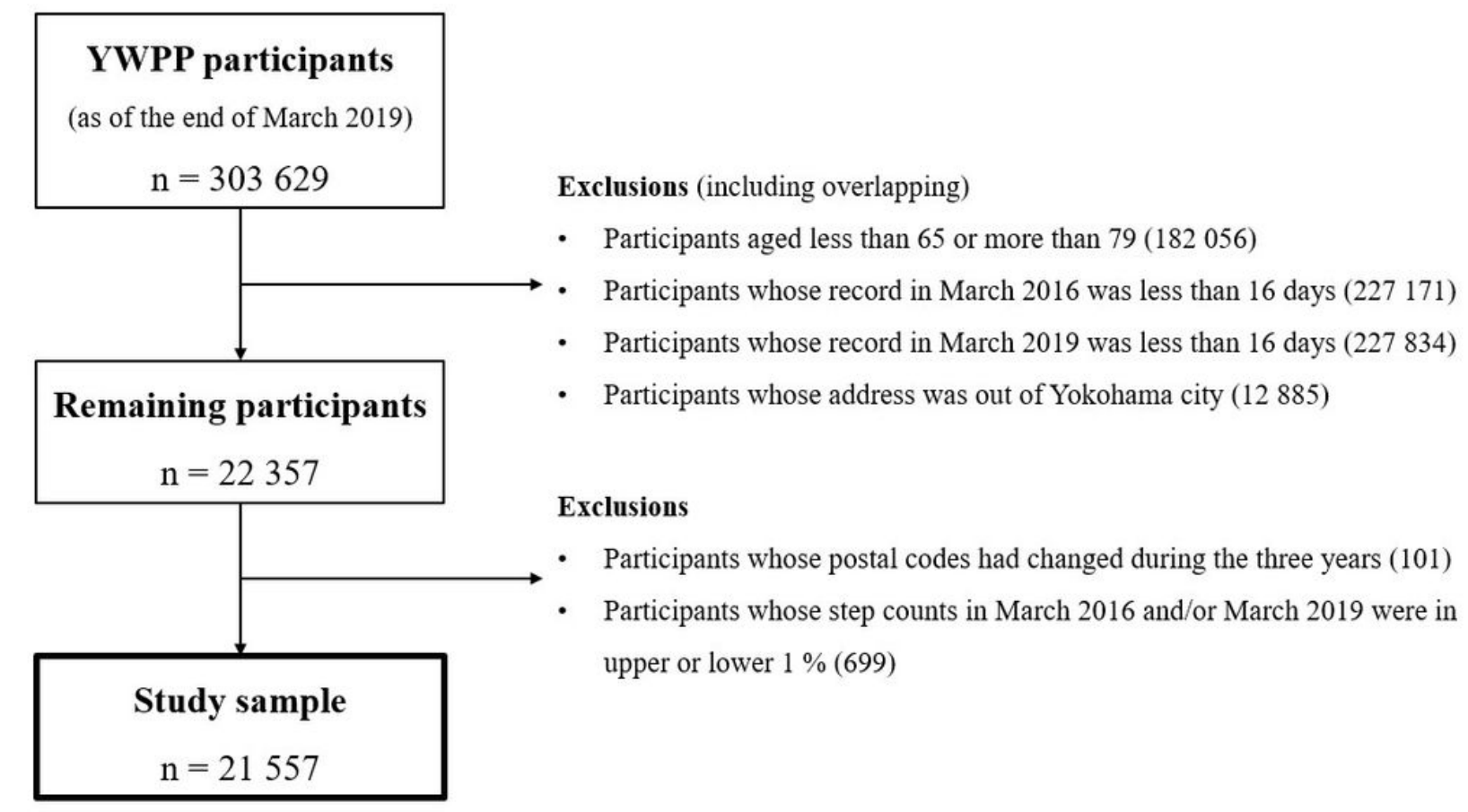

\section{Figure 2}

Sample selection flow diagram 